\title{
INVESTIGATION OF THE ENERGY EFFECTIVENESS OF MULTISTAGE DIFFERENTIAL GEARS WHEN THE SPEED IS CHANGED BY THE CARRIER
}

\author{
Volodymyr MALASHCHENKO, Oleh STRILETS, Volodymyr STRILETS, Sylwester KLYSZ
}

Lviv Polytechnic National University, Lviv, Ukraine, volod.malash@gmail.com

National University of Water And Environmental Engineering, Rivne, Ukraine, o.r.strilets@ nuwm.edu.ua University of Warmia and Mazury, Olsztyn, Air Force Institute of Technology, Warszawa, Poland, sylwesterklysz3@gmail.com

\begin{abstract}
The energy effectiveness of the multistage gear differential in the device for speed change by carrier has been investigated with the determination of the efficiency. Considering complexity of the problem, the analytical methods of efficiency determining for two- and three-stage differential gears have been obtained and proposed using the potential power method, when the driving link is the first-stage sun gear, the driven link is the ring gear of the last stage or vice versa, and the links of the speed change control are the carriers of the individual stages. With the help of computer modeling of analytical expressions, graphical dependences of efficiency from the ratio of the multistage differential gear and the angular velocity of the control link - the carrier, have been obtained. The results obtained have practical application for the design of new devices by means of energy effectiveness, allow to evaluate the operation of multistage differential gears from the point of view of self-breaking and are of assistance for further research.
\end{abstract}

Keywords: energy effectiveness, efficiency, multi-stage differential gear, speed change device, sun gear, planet, ring gear, carrier, closed circuit hydrosystem.

\section{ACTUALITY AND STATEMENT OF THE PROBLEM}

During the implementation of technological operations by the hoisting-transport, building, road, land reclamation, agricultural, mining and other machines, cars and tractors, metalworking machines, water and air crafts and other devices, the need arises to control the process of changing the speed of their working organ to ensure the specified technological processes. In order to change the speed in modern machinery, methods and devices are widely used in the form of stepped, stepless or combined gear boxes. Existing speed management methods and devices have many shortcomings. The main disadvantages of stepped speed control are the complexity of the design and automatization of these devices, their large material capacity, large dynamic loads that arise when shifting from one speed to another, even in synchromesh gear-boxes. In stepless speed control there is a great deal of wear of the drive elements due to the use of friction brakes and locking friction clutches. As a result, the durability and reliability of drive elements and machines in general decreases. Therefore, there is a problem of creating new speed change management methods and devices that eliminate these shortcomings. The proposed new methods and devices for speed changes control are based on multistage differential gears with closed circuit hydrosystems. This requires their kinematic, power and energy research. All the machinery mentioned at the beginning are a potential example for the use of such devices.

\section{ANALYSIS OF RECENT RESEARCH AND PUBLICATIONS}

The problem of developing new devices for the speed change is obvious and is a subject of special interest of world scientists. In [1], the theoretical effectiveness formulas for the two-stage differential gear transmission were obtained and verified by experimental studies. The design of a bi-planetary transmission was presented in [2], with the calculations of the kinematics, statics and efficiency of gearing. Omitted from the calculation are the geometry and strength of gears, shafts and rolling bearings, as these are recognized as being typical design calculations. On the basis of the torque, power balance equations and force analysis of the basic members, the power distributions of a $2 \mathrm{~K}-\mathrm{H}$ multistage micro-planetary gear reducer are analyzed in [3]. In [4], authors suggest an algorithm to resolve the problem of degenerate planetary gear train detection, automated by an interactive computer program. The algorithm is applicable for transmissions with any number of degree of freedoms. A new method to calculate gear kinematic and power parameters was proposed in [5], based on hypergraph and matrix operation. PE computation is carried out by 
following the power flow, and power loss equations on each node are derived via an approach based on self-rotation relative power. In [6], a joint analysis was held of the efficiency ranges and the transmission coefficient of planetary transmissions, which can be achieved by any possible constructive solutions. The results of dynamical model verifying for the drive with a gearbox, that was conducted on a real object in different operating conditions and stimulation studies to determine the suitability of the model, but without taking into account the energy efficiency, were given in [7]. The performance efficiency of complex gear transmissions is investigated in [8], on the basis of graphic and screw theories, which allow obtaining approximate values. In [9], the reduction in the construction cost of many high-speed planetary gear trains based on system synthesis is justified taking into account such requirements as the gear ratio, performance efficiency, planarity of the mechanism and one shifting, for heavy goods vehicles. The attention was drawn in [10] to the full understanding of the basic mechanics of planetary transmissions and the evaluation of their mechanical efficiency, and it is concluded that for the same input and output units power loss has a peculiar mathematical expression for each actual sequence of angular velocities. In [11] the reasons that hinder the application of smoothly controlled planetary transmission, due to the structural complexity of ratio control device and variants to simplify it described, and in [12], attention was drawn to the fact that planetary transmissions are used in the industry for many benefits, which include high torque, increased efficiency and a very compact drive, and as made of gears - the failure of one link affects the whole transmission, so you need to know the reasons. The average performance of an internal combustion engine is evaluated on models with a stepped and stepless gearbox in [13], and in particular, article indicates that the architecture with transmissions based on the planetary train sets allows the engine to operate in optimal conditions. In [14], a composite power losses model in geared transmissions was developed and a study of the influence of the design parameters of planetary gear trains, bearings and lubrication properties on productivity was carried out.

The analysis of the problem shows that it is more rational to use differential gears, which are widely described in classical literature for example, [15-17], that consider the structure, synthesis and analysis, kinematic and power issues of planetary type gear transmissions. Periodical technical literature [18-21] has proposed a new stepless method for speed changes control by the singlestage differential gears with closed circuit hydrosystems and its kinematics research. In [18], the current state of the methods and devices for the speed change process controlling in technology has been analyzed, a new method of continuously variable speed changes control using differential gear transmissions with a closed circuit hydrosystems has been proposed, and a new classification given. A new method of continuously variable speed changes control using differential gears with a closed circuit hydrosystems has been described, for cases when the control link is either a sun gear, or a carrier, or a ring gear. In [19], the process of controlling changes in speed through a differential gear with a closed circuit hydrosystem has been considered, when the sun gear is the driving link and the carrier is driven or vice versa, and the control link is the ring gear. With the help of computer simulation graphical dependencies has been obtained between the speeds of the driving, controlling and driven links.

In [20], the process of controlling changes in speed through a two-planets set differential gear with a closed circuit hydrosystem has been considered, when the control link is either the ring gear, or the carrier, or the sun gear. For each case, graphical dependencies has been obtained between the speeds of the driving, controlling and driven links by means of computer programming. To extend the range of speed changes in machine drives, it has been proposed to use multistage differential gears consisting of two or more connected stages. At scientific and technical conferences, symposiums and other scientific discussions, questions are often asked about the performance efficiency coefficient (PE) of such transmissions to assess their energy efficiency, depending on the gear ratio, the speed of the control link and the number of stages. The purpose of the work is to conduct a theoretical-computer study of energy effectiveness of new devices by determining their performance efficiency coefficient. The object of research includes multistage differential gears of speed change devices with closed circuit hydrosystems. In this case, the driving link is the sun gear of the first stage, the driven - is the ring gear of the last stage, or vice versa, and the control links are the carriers of the individual stages. It is supposed with the help of computer modeling of analytical expressions to obtain graphical dependences of the PE from the ratio of the multistage differential gear and the angular speed of the control link - the carrier and to develop their practical application.

\section{STATEMENT OF THE MAIN MATERIAL}

The Fig. 1 shows a multistage $(i=1,2,3, \ldots, n)$ differential gear in which the first stage ring gear $3_{(1)}$ is connected to a second-stage sun gear $1_{(2)}$, the second stage ring gear $3_{(2)}$ is connected to the third stage sun gear $1_{(3)}, \ldots$, the $(n-1)$-stage ring gear $3_{(\mathrm{n}-}$ 1) is connected to the $n$-stage sun gear $1_{(n)}$, and speed control is carried out by the carriers of the first $4_{(1)}$, the second $4_{(2)}$, the third $4_{(3)}, \ldots$, and the $n$ th $4_{(n)}$ stages with the help of the closed circuit 
hydrosystems $6_{(1)}, 6_{(2)}, 6_{(3)}, \ldots, 6_{(n)}$, installed respectively. Closed circuit hydrosystems $6_{(1)}, 6_{(2)}$, $6_{(3)}, \ldots, 6_{(n)}$ of the same structure are placed on the body 5 and connected to the carriers $4_{(1)}, 4_{(2)}, 4_{(3)}$, $\ldots, 4_{(n)}$ through gearings $7_{(1)}, 7_{(2)}, 7_{(3)}, \ldots, 7_{(n)}$.

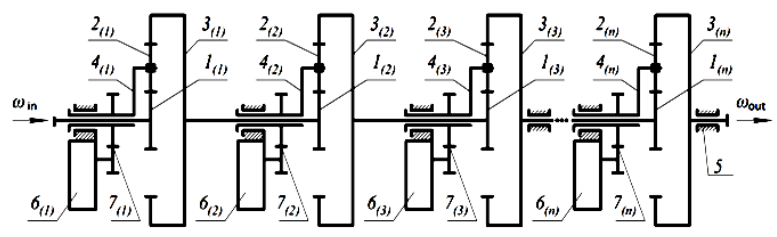

Fig. 1. Scheme of a multistage differential gear with closed circuit hydrosystems with speed control by the carriers and driving sun gear

The closed circuit hydrosystem and its operation is fully described in [18] and consists of a gear pump, pipelines, regulating throttle, reverse valve and a liquid container. When regulating throttle is open, then the carrier rotates, the fluid is pumped in a closed circuit hydrosystem. In the case when regulating throttle is closed - the carrier stops, and the liquid is not pumped in the hydrosystem, because it is closed. Therefore, speed change control is carried out by the regulating throttle and the liquid which moves in a closed circuit hydrosystem.

The driving link of this multistage differential gear is the first-stage sun gear $1_{(1)}$, and the driven link is the ring gear $3_{(\mathrm{n})}$ of the $n$-th stage. Expressions of the relationship between the speeds of the driven link (the ring gear $3_{(n)}$ ) $\omega_{\text {out }}$ and the driving link (sun gear $1_{(1)}$ ) $\omega_{\text {in }}$ have been obtained in [21].

There, the transmission efficiency $\eta_{1(1)-3(n)}$ is described by the expression:

$\eta_{13(1)-13(n)}=\eta_{13(1)} \eta_{13(2)} \eta_{13(3)} \cdots \eta_{13(n)}$

where $\eta_{13(n)}$ - efficiency of the $n$-th stage.

According to [12], the efficiency of the individual stages is determined by:

$$
\begin{aligned}
& \eta_{13(1)}=\frac{\left[\omega_{1(1)}-\omega_{4(1)}\left(1+u_{13(1)}^{(4)}\right)\right] \eta_{13(1)}^{(4)}}{\omega_{1(1)}-\omega_{4(1)}\left(1+u_{13(1)}^{(4)} \eta_{13(1)}^{(4)}\right)} ; \\
& \eta_{13(2)}=\frac{\left[\omega_{1(2)}-\omega_{4(2)}\left(1+u_{13(2)}^{(4)}\right)\right] \eta_{13(2)}^{(4)}}{\omega_{1(2)}-\omega_{4(2)}\left(1+u_{13(2)}^{(4)} \eta_{13(2)}^{(4)}\right)} ; \\
& \eta_{13(3)}=\frac{\left[\omega_{1(3)}-\omega_{4(3)}\left(1+u_{13(3)}^{(4)}\right)\right] \eta_{13(3)}^{(4)}}{\omega_{1(3)}-\omega_{4(3)}\left(1+u_{13(3)}^{(4)} \eta_{13(3)}^{(4)}\right)} ; \\
& \ldots ; \\
& \eta_{13(n)}=\frac{\left[\omega_{1(n)}-\omega_{4(n)}\left(1+u_{13(n)}^{(4)}\right)\right] \eta_{13(n)}^{(4)}}{\omega_{1(n)}-\omega_{4(n)}\left(1+u_{13(n)}^{(4)} \eta_{13(n)}^{(4)}\right)},
\end{aligned}
$$

where $\omega_{1(n)}-$ the angular velocities of the sun gears of the $n$-th stage;

$\omega_{4(n)}$ - the angular velocities of the carriers of the $n$-th stage; $u_{13(n)}^{(4)}-$ transmissions gear ratios with a stopped carrier of the $n$-th stage;

$\eta_{13(n)}^{(4)}$ - efficiency transmissions gear ratios with a stopped carrier of the $n$-th stage.

Fig. 2 shows a multistage $(i=1,2,3, \ldots, n)$ differential gear with driving link - ring gear of the first stage and the driven - the sun gear of the last stage. Here the first stage sun gear $1_{(1)}$ is connected to a second-stage ring gear $3_{(2)}$, the second stage sun gear $1_{(2)}$ is connected to the third stage ring gear $3_{(3)}, \ldots$, the $(n-1)$-stage sun gear $1_{(\mathrm{n}-1)}$ is connected to the $n$-stage ring gear $3_{(n)}$, and speed control is carried out by the carriers of the first $4_{(1)}$, the second $4_{(2)}$, the third $4_{(3)}, \ldots$, and the $n$-th $4_{(n)}$ stages with the help of the closed circuit hydrosystems $6_{(1)}, 6_{(2)}, 6_{(3)}, \ldots, 6_{(n)}$, installed respectively. Closed circuit hydrosystems $6_{(1)}, 6_{(2)}$, $6_{(3)}, \ldots, 6_{(n)}$ of the same structure are placed on the body 5 and connected to the carriers $4_{(1)}, 4_{(2)}, 4_{(3)}$, $\ldots, 4_{(n)}$ through gearings $7_{(1)}, 7_{(2)}, 7_{(3)}, \ldots, 7_{(n)}$.

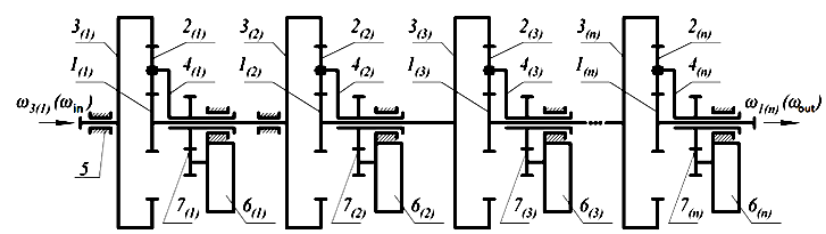

Fig. 2. Scheme of a multistage differential gear with closed circuit hydrosystems with speed control by the carriers and driving ring gear

The expression of efficiency $\eta_{3(1)-1(n)}$ of transmission (Fig. 2) has the form:

$\eta_{31(1)-31(n)}=\eta_{31(1)} \eta_{31(2)} \eta_{31(3)} \cdots \eta_{31(n)}$,

where $\eta_{31(n)}$ - efficiency of the $n$-th stage.

The efficiency of the individual stages, according to [12], will be:

$\eta_{31(1)}=\frac{\left[\omega_{3(1)} u_{13(1)}^{(4)}-\omega_{4(1)}\left(1+u_{13(1)}^{(4)}\right)\right] \eta_{13(1)}^{(4)}}{\omega_{3(1)} u_{13(1)}^{(4)}-\omega_{4(1)}\left(\eta_{13(1)}^{(4)}+u_{13(1)}^{(4)}\right)} ;$

$\eta_{31(2)}=\frac{\left[\omega_{3(2)} u_{13(2)}^{(4)}-\omega_{4(2)}\left(1+u_{13(2)}^{(4)}\right)\right] \eta_{13(2)}^{(4)}}{\omega_{3(2)} u_{13(2)}^{(4)}-\omega_{4(2)}\left(\eta_{13(2)}^{(4)}+u_{13(2)}^{(4)}\right)}$;

$\eta_{31(3)}=\frac{\left[\omega_{3(3)} u_{13(3)}^{(4)}-\omega_{4(3)}\left(1+u_{13(3)}^{(4)}\right)\right] \eta_{13(3)}^{(4)}}{\omega_{3(3)} u_{13(3)}^{(4)}-\omega_{4(3)}\left(\eta_{13(3)}^{(4)}+u_{13(3)}^{(4)}\right)}$;

$\eta_{31(n)}=\frac{\left[\omega_{3(n)} u_{13(n)}^{(4)}-\omega_{4(n)}\left(1+u_{13(n)}^{(4)}\right)\right] \eta_{13(n)}^{(4)}}{\omega_{3(n)} u_{13(n)}^{(4)}-\omega_{4(n)}\left(\eta_{13(n)}^{(4)}+u_{13(n)}^{(4)}\right)}$,

where $\omega_{3(n)}-$ the angular velocities of the ring gears of the $n$-th stage;

$\omega_{4(n)}$ - the angular velocities of the carriers of the $n$-th stage;

$u_{13(n)}^{(4)}-$ transmissions gear ratios with a stopped carrier of the $n$-th stage; 
$\eta_{31(n)}^{(4)}$ - efficiency transmissions gear ratios with a stopped carrier of the $n$-th stage.

Considering the complexity of the problem, a theoretical computer study of the efficiency of a multistage differential gear in a speed change device with closed circuit hydrosystems is performed here, using examples of two- and threestage gears.

Fig. 3 shows a two-stage differential gear in which the first stage ring gear $3_{(1)}$ is connected to a second-stage sun gear $1_{(2)}$, and speed control is carried out by the carriers of the first $4_{(1)}$ and the second $4_{(2)}$ stages with the help of the closed circuit hydrosystems $6_{(1)}, 6_{(2)}$.

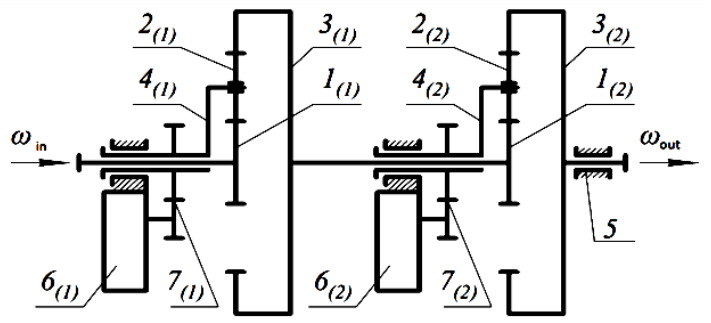

Fig. 3. Scheme of a two-stage differential gear with closed circuit hydrosystems with speed control by the carriers and driving sun gear

The driving link of this two-stage differential gear is the first-stage sun gear $1_{(1)}$, and the driven link is the second-stage ring gear $3_{(2)}$. Relationship between the speeds of the driven link (the ring gear $\left.3_{(2)}\right) \omega_{\text {out }}$ and the driving link (sun gear $\left.1_{(1)}\right) \omega_{\text {in }}$ have been obtained in [21]. Here, $\omega_{4(1)}$ and $\omega_{4(2)}-$ velocities of the carriers, respectively, of the first $4_{(1)}$ and the second $4_{(2)}$ stages, which vary due to the closed circuit hydrosystems $6_{(1)}$ and $6_{(2)}$.

The expression for the efficiency $\eta_{13}$ of such transmission is:

$\eta_{13}=\eta_{13(1)} \eta_{13(2)}$.

The efficiency of the individual stages, according to [12], will be:

$$
\begin{aligned}
& \eta_{13(1)}=\frac{\left[\omega_{1(1)}-\omega_{4(1)}\left(1+u_{13(1)}^{(4)}\right)\right] \eta_{13(1)}^{(4)}}{\omega_{1(1)}-\omega_{4(1)}\left(1+u_{13(1)}^{(4)} \eta_{13(1)}^{(4)}\right)} ; \\
& \eta_{13(2)}=\frac{\left[\omega_{1(2)}-\omega_{4(2)}\left(1+u_{13(2)}^{(4)}\right)\right] \eta_{13(2)}^{(4)}}{\omega_{1(2)}-\omega_{4(2)}\left(1+u_{13(2)}^{(4)} \eta_{13(2)}^{(4)}\right)} .
\end{aligned}
$$

If we assume that

$$
\omega_{1(2)}=\omega_{3(1)}=\frac{\omega_{4(1)}\left(1+u_{13(1)}^{(4)}\right)-\omega_{1(1)}}{u_{13(1)}^{(4)}},
$$

insert it in (7), and substitute the values (6) and (7) in (5), we obtain the expression for determining the efficiency of the two-stage differential gear in the device for speed change by the carrier when the driving sun gear, and the driven ring gear

$$
\begin{aligned}
& \eta_{13}=\frac{\left[\omega_{1(1)}-\omega_{4(1)}\left(1+u_{13(1)}^{(4)}\right)\right] \eta_{13(1)}^{(4)}}{\omega_{1(1)}-\omega_{4(1)}\left(1+u_{13(1)}^{(4)} \eta_{13(1)}^{(4)}\right)} \times \\
& \times \frac{\left[\omega_{1(1)}-\omega_{4(1)}\left(1+u_{13(1)}^{(4)}\right)+\omega_{4(2)}\left(1+u_{13(2)}^{(4)}\right) u_{13(1)}^{(4)}\right] \eta_{13(2)}^{(4)}}{\omega_{1(1)}-\omega_{4(1)}\left(1+u_{13(1)}^{(4)}\right)+\omega_{4(2)}\left(1+u_{13(2)}^{(4)} \eta_{13(2)}^{(4)}\right) u_{13(1)}^{(4)}} .
\end{aligned}
$$

In order to carry out a quantitative analysis of the efficiency change, expression (15) has been programmed on computer for such parameters:

- the angular velocity of the driving link - the sun gear $\omega_{1(1)}=75 ; 100 ; 150 ; 300 \mathrm{rad} / \mathrm{s}$;

- the gear ratios of the stages with stopped carrier are equal and change in a range $u_{13(1)}^{(4)}=u_{13(2)}^{(4)}=1,0 \ldots 10$;

- angular speed of control links - carriers are $\omega_{4(1)}=\omega_{4(2)}=0 . .50 \mathrm{rad} / \mathrm{s}$;

- efficiency of gears with stopped carrier $\eta_{13(1)}^{(4)}=\eta_{13(2)}^{(4)}=0,97$.

For these data, graphical dependences of the efficiency have been built, some of them are shown in Fig. 4.

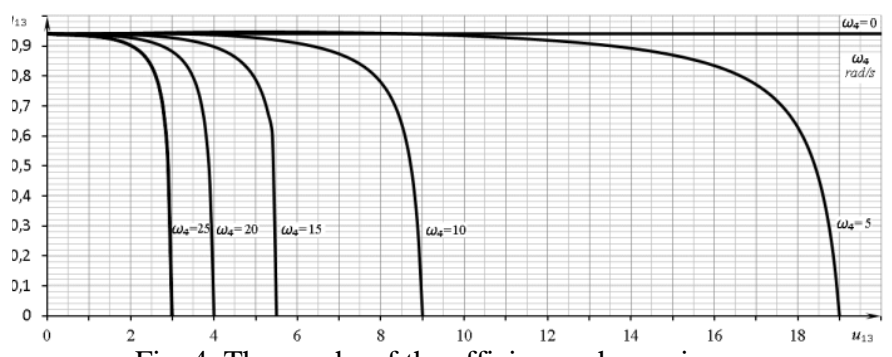

Fig. 4. The graphs of the efficiency change in a two-stage differential gear with the driving sun gear and the driven ring gear of the second stage,

depending on the ratio and speed of the control link - the carrier

One of many possible potential models for speed change control device based on fig. 3 - a two-stage differential gear with closed circuit hydrosystems and control through the carrier is shown in Fig. 5.

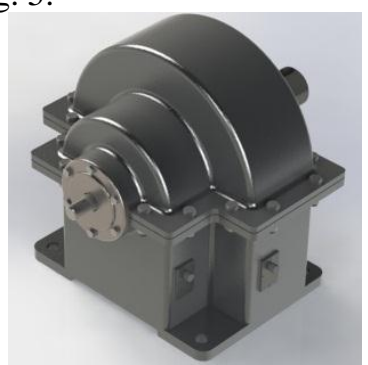

Fig. 5. Model for device with a two-stage differential gear with closed circuit hydrosystems and control through the carrier

Such speed change devices can be modeled for the place of their application with the help of computer 3-D modeling in a plurality of variants and choose the optimal one for which to carry out design and construction. For example, for a given model, the mount is shown using a lower belt, but 
there may be a top, side or flange mount. It depends on the case.

Now let's take the first-stage ring gear $3_{(1)}$ of the two-stage differential gear as a driving link, and the second-stage sun gear $1_{(2)}$ will be driven. Here the solar gear $1_{(1)}$ is connected to the ring gear $3_{(2)}$, and the speed control links are the carriers $4_{(1)}$ and $4_{(2)}$.

The expression of efficiency $\eta_{31}$ of transmission (Fig. 6) is:

$$
\begin{aligned}
& \eta_{31}=\eta_{31(1)} \eta_{31(2)} \\
& \eta_{31(1)}=\frac{\left[\omega_{3(1)} u_{13(1)}^{(4)}-\omega_{4(1)}\left(1+u_{13(1)}^{(4)}\right)\right] \eta_{13(1)}^{(4)}}{\omega_{3(1)} u_{13(1)}^{(4)}-\omega_{4(1)}\left(\eta_{13(1)}^{(4)}+u_{13}^{(4)}\right)} ; \\
& \eta_{31(2)}=\frac{\left[\omega_{3(2)} u_{13(2)}^{(4)}-\omega_{4(2)}\left(1+u_{13(2)}^{(4)}\right)\right] \eta_{13(2)}^{(4)}}{\omega_{3(2)} u_{13(2)}^{(4)}-\omega_{4(2)}\left(\eta_{13(2)}^{(4)}+u_{13(2)}^{(4)}\right)} \cdot
\end{aligned}
$$

Fig. 6. Scheme of a two-stage differential gear with closed circuit hydrosystems with speed control by the carriers and driving ring gear

If we assume that

$\omega_{3(2)}=\omega_{1(1)}=\omega_{4(1)}\left(1+u_{13(1)}^{(4)}\right)-\omega_{3(1)} u_{13(1)}^{(4)}$,

insert it in (12), and substitute the values (11) and (12) in (10), we obtain the expression for determining the efficiency of the two-stage differential gear in the device for speed change by the carrier when the driving ring gear, and the driven sun gear:

$$
\begin{aligned}
& \eta_{31}=\frac{\left[\omega_{3(1)} u_{13(1)}^{(4)}-\omega_{4(1)}\left(1+u_{13(1)}^{(4)}\right)\right] \eta_{13(1)}^{(4)}}{\omega_{3(1)} u_{13(1)}^{(4)}-\omega_{4(1)}\left(\eta_{13(1)}^{(4)}+u_{13}^{(4)}\right)} \times \\
& \times \frac{\left\{\left[\omega_{4(1)}\left(1+u_{13(1)}^{(4)}\right)-\omega_{3(1)} u_{13(1)}^{(4)}\right] u_{13(2)}^{(4)}-\omega_{4(2)}\left(1+u_{13(2)}^{(4)}\right)\right\} \eta_{13(2)}^{(4)}}{\left[\omega_{4(1)}\left(1+u_{13(1)}^{(4)}\right)-\omega_{3(1)} u_{13(1)}^{(4)}\right] u_{13(2)}^{(4)}-\omega_{4(2)}\left(\eta_{13(2)}^{(4)}+u_{13(2)}^{(4)}\right)}
\end{aligned}
$$

For convenience, the results for the efficiency of the two-stage gear differential from the ring gear to the sun gear, the formula (20) has been programmed using the previous numerical values. The results are shown in Fig. 7.

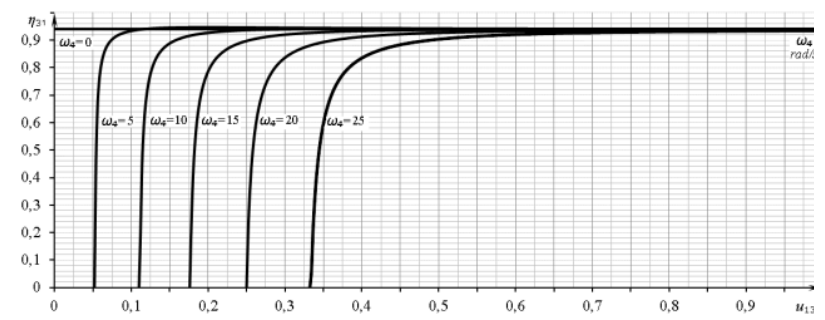

Fig. 7. The graphs of the efficiency change in a twostage differential gear with the driving ring gear and the driven sun gear of the second stage, depending on the ratio and speed of the control link - the carrier
Fig. 8 shows a three-stage differential gear. It is built so that the first stage ring gear $3_{(1)}$ is connected to a second-stage sun gear $1_{(2)}$. The second stage ring gear $3_{(2)}$ is connected to the third stage sun gear $1_{(3)}$. Speed control is carried out by the carriers of the first $4_{(1)}$, the second $4_{(2)}$ and the third $4_{(3)}$ stages with the help of the closed circuit hydrosystems $6_{(1)}, 6_{(2)}, 6_{(3)}$. Consider the case where the driving link of this three-stage differential gear is the first-stage sun gear $1_{(1)}$, and the driven link is the third-stage ring gear $3_{(2)}$.

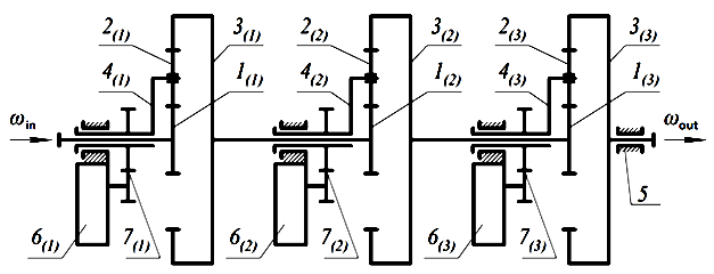

Fig. 8. Scheme of a three-stage differential gear with closed circuit hydrosystems with speed control by the carriers and driving sun gear

The expression for the efficiency $\eta_{13}$ of such trans-mission is:

$\eta_{13}=\eta_{13(1)} \eta_{13(2)} \eta_{13(3)}$

The efficiency of individual stages can be determined:

$$
\begin{aligned}
& \eta_{13(1)}=\frac{\left[\omega_{1(1)}-\omega_{4(1)}\left(1+u_{13(1)}^{(4)}\right)\right] \eta_{13(1)}^{(4)}}{\omega_{1(1)}-\omega_{4(1)}\left(1+u_{13(1)}^{(4)} \eta_{13(1)}^{(4)}\right)} ; \\
& \eta_{13(2)}=\frac{\left[\omega_{1(2)}-\omega_{4(2)}\left(1+u_{13(2)}^{(4)}\right)\right] \eta_{13(2)}^{(4)}}{\omega_{1(2)}-\omega_{4(2)}\left(1+u_{13(2)}^{(4)} \eta_{13(2)}^{(4)}\right)} ; \\
& \eta_{13(3)}=\frac{\left[\omega_{1(3)}-\omega_{4(3)}\left(1+u_{13(3)}^{(4)}\right)\right] \eta_{13(3)}^{(4)}}{\omega_{1(3)}-\omega_{4(3)}\left(1+u_{13(3)}^{(4)} \eta_{13(3)}^{(4)}\right)} .
\end{aligned}
$$

If we assume that

$$
\begin{aligned}
& \omega_{1(2)}=\omega_{3(1)}=\frac{\omega_{4(1)}\left(1+u_{13(1)}^{(4)}\right)-\omega_{1(1)}}{u_{13(1)}^{(4)}} ; \\
& \omega_{1(3)}=\omega_{3(2)}=\frac{\omega_{4(2)}\left(1+u_{13(2)}^{(4)}\right) u_{13(1)}^{(4)}+\omega_{1(1)}-\omega_{4(1)}\left(1+u_{13(1)}^{(4)}\right.}{u_{13(2)}^{(4)} u_{13(1)}^{(4)}},
\end{aligned}
$$

insert it in (23) and (24), and substitute the values (22), (23) and (24) in (21), we obtain the expression for determining the efficiency of the three-stage differential gear in the device for speed change by the carrier when the driving sun gear, and the driven ring gear:

$\eta_{13}=\frac{\left[\omega_{1(1)}-\omega_{4(1)}\left(1+u_{13(1)}^{(4)}\right)\right] \eta_{13(1)}^{(4)}}{\omega_{1(1)}-\omega_{4(1)}\left(1+u_{13(1)}^{(4)} \eta_{13(1)}^{(4)}\right)} \times$

$$
\begin{aligned}
& \times \frac{\left[\omega_{1(1)}-\omega_{4(1)}\left(1+u_{13(1)}^{(4)}\right)+\omega_{4(2)}\left(1+u_{13(2)}^{(4)}\right) u_{13(1)}^{(4)}\right] \eta_{13(2)}^{(4)}}{\omega_{1(1)}-\omega_{4(1)}\left(1+u_{13(1)}^{(4)}\right)+\omega_{4(2)}\left(1+u_{13(2)}^{(4)} \eta_{13(2)}^{(4)}\right) u_{13(1)}^{(4)}} \times \\
& \times \frac{\left[\omega_{4(2)}\left(1+u_{13(2)}^{(4)}\right) u_{13(1)}^{(4)}+\omega_{1(1)}-\omega_{4(1)}\left(1+u_{13(1)}^{(4)}\right)-\omega_{4(3)}\left(1+u_{13(3)}^{(4)}\right) u_{13(2)}^{(4)} u_{13(1)}^{(4)}\right] \eta_{13(3)}^{(4)}}{\omega_{4(2)}\left(1+u_{13(2)}^{(4)}\right) u_{13(1)}^{(4)}+\omega_{1(1)}-\omega_{4(1)}\left(1+u_{13(1)}^{(4)}\right)-\omega_{4(3)}\left(1+u_{13(3)}^{(4)} \eta_{13(3)}^{(4)}\right) u_{13(2)}^{(4)} u_{13(1)}^{(4)}} .
\end{aligned}
$$

For a quantitative analysis of the efficiency change, expression (27) has been programmed on computer for such parameters: 
- the angular velocity of the driving link - the sun gear $\omega_{1(1)}=75 ; 100 ; 150 ; 300 \mathrm{rad} / \mathrm{s}$;

- the gear ratios of the stages with stopped carrier are equal and change in a range $u_{13(1)}^{(4)}=u_{13(2)}^{(4)}=u_{13(3)}^{(4)}=1,0 \ldots 10$;

- angular speed of control links - carriers are $\omega_{4(1)}=\omega_{4(2)}=\omega_{4(3)}=0 . .50 \mathrm{rad} / \mathrm{s}$;

- efficiency of gears with stopped carrier $\eta_{13(1)}^{(4)}=\eta_{13(2)}^{(4)}=\eta_{13(3)}^{(4)}=0,97$.

For these data, graphical dependences of the efficiency have been built, some of them are shown in Fig. 9.

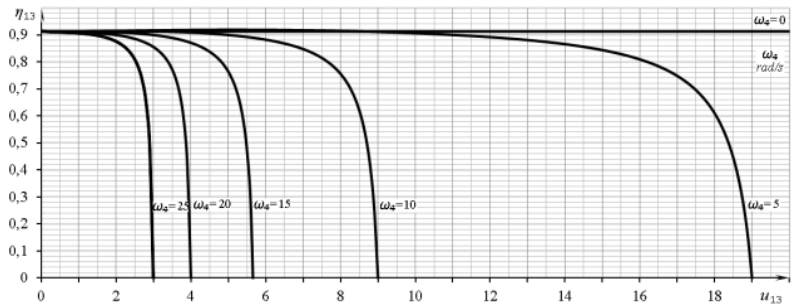

Fig. 9. The graphs of the efficiency change in a three-stage differential gear with the driving sun gear and the driven ring gear of the third stage, depending on the ratio and speed of the control link - the carrier

When the driving link is a first-stage ring gear $3_{(1)}$, and the driven link is a third-stage sun gear $1_{(2)}$, the three-stage differential gear will take the form as in Fig. 10.

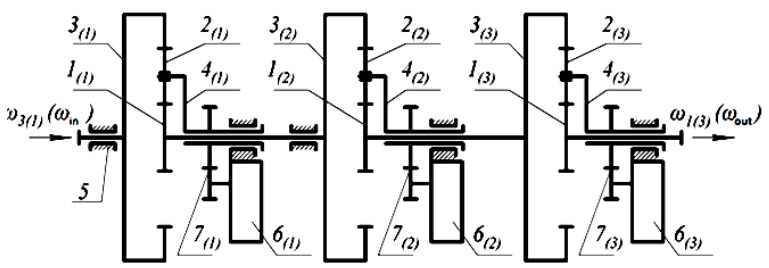

Fig. 10. Scheme of a three-stage differential gear with closed circuit hydrosystems with speed control by the carriers and driving ring gear

The expression of efficiency $\eta_{31}$ of such transmission will be:

$$
\begin{aligned}
& \eta_{31}=\eta_{31(1)} \eta_{31(2)} \eta_{31(3)} \\
& \eta_{31(1)}=\frac{\left[\omega_{3(1)} u_{13(1)}^{(4)}-\omega_{4(1)}\left(1+u_{13(1)}^{(4)}\right)\right] \eta_{13(1)}^{(4)}}{\omega_{3(1)} u_{13(1)}^{(4)}-\omega_{4(1)}\left(\eta_{13(1)}^{(4)}+u_{13}^{(4)}\right)} ; \\
& \eta_{31(2)}=\frac{\left[\omega_{3(2)} u_{13(2)}^{(4)}-\omega_{4(2)}\left(1+u_{13(2)}^{(4)}\right)\right] \eta_{13(2)}^{(4)}}{\omega_{3(2)} u_{13(2)}^{(4)}-\omega_{4(2)}\left(\eta_{13(2)}^{(4)}+u_{13(2)}^{(4)}\right)} ; \\
& \eta_{31(3)}=\frac{\left[\omega_{3(3)} u_{13(3)}^{(4)}-\omega_{4(3)}\left(1+u_{13(3)}^{(4)}\right)\right] \eta_{13(3)}^{(4)}}{\omega_{3(3)} u_{13(3)}^{(4)}-\omega_{4(3)}\left(\eta_{13(3)}^{(4)}+u_{13(3)}^{(4)}\right)} .
\end{aligned}
$$

If we assume that

$$
\begin{gathered}
\omega_{3(2)}=\omega_{1(1)}=\omega_{4(1)}\left(1+u_{13(1)}^{(4)}\right)-\omega_{3(1)} u_{13(1)}^{((4)} ; \\
\omega_{3(3)}=\omega_{1(2)}=\omega_{4(2)}\left(1+u_{13(2)}^{(4)}\right)-\left[\omega_{4(1)}\left(1+u_{13(1)}^{(4)}\right)-\omega_{3(1)} u_{13(1)}^{(4)}\right] u_{13(2)}^{((4)},
\end{gathered}
$$

nsert it in (30) and (31), and substitute the values (39), (30) and (31) in (28), we obtain the expression for determining the efficiency of the three-stage differential gear in the device for speed change by the carrier when the driving ring gear, and the driven sun gear

$\eta_{31}=\frac{\left[\omega_{3(1)} u_{13(1)}^{(4)}-\omega_{4(1)}\left(1+u_{13(1)}^{(4)}\right)\right] \eta_{13(1)}^{(4)}}{\omega_{3(1)} u_{13(1)}^{(4)}-\omega_{4(1)}\left(\eta_{13(1)}^{(4)}+u_{13}^{(4)}\right)} \times$

$\times \frac{\left\{\left[\omega_{4(1)}\left(1+u_{13(1)}^{(4)}\right)-\omega_{3(1)} u_{13(1)}^{(4)}\right] u_{13(2)}^{(4)}-\omega_{4(2)}\left(1+u_{13(2)}^{(4)}\right)\right\} \eta_{13(2)}^{(4)} \times}{\left[\omega_{4(1)}\left(1+u_{1(1)}\right)-\omega_{(1)} u_{1(1)}\right) u_{(3)}-\omega_{42}\left(\eta_{1(2)}^{(4)}+u_{1(2)}\right)}$

$\left[\omega_{4(1)}\left(1+u_{13(1)}^{(4)}\right)-\omega_{3(1)} u_{13(1)}^{(4)}\right] u_{13(2)}^{(4)}-\omega_{4(2)}\left(\eta_{13(2)}^{(4)}+u_{13(2)}^{(4)}\right)$

$\times \frac{\left\{\left\{\omega_{4(2)}\left(1+u_{13(2)}^{(4)}\right)-\left[\omega_{4(1)}\left(1+u_{13(1)}^{(4)}\right)-\omega_{3(1)} u_{13(1)}^{(4)}\right] u_{13(2)}^{(4)}\right\} u_{13(3)}^{(4)}-\omega_{4(3)}\left(1+u_{13(3)}^{(4)}\right\} \eta_{13(3)}^{(4)}\right.}{\left\{\omega_{4(2)}\left(1+u_{13(2)}\right.\right.}$.

$\left\{\omega_{4(2)}\left(1+u_{13(2)}^{(4)}\right)-\left[\omega_{4(1)}\left(1+u_{13(1)}^{(4)}\right)-\omega_{3(1)} u_{13(1)}^{(4)}\right] u_{13(2)}^{(4)}\right\} u_{13(3)}^{(4)}-\omega_{4(3)}\left(\eta_{13(3)}^{(4)}+u_{13(3)}^{(4)}\right)$

For greater clarity of the nature of efficiency change in the of the three-stage differential gear from the ring gear to the sun gear, the expression (34) has been programmed, and if we give the initial data analogical to the previous case, we obtain:

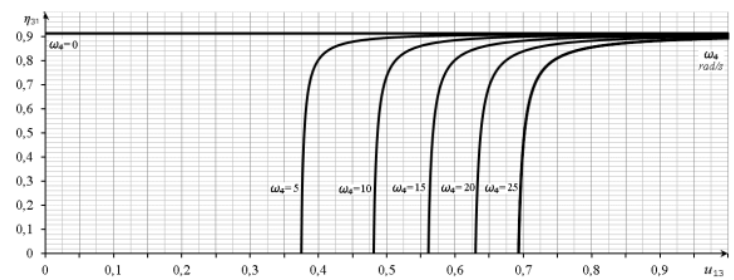

Fig. 11. The graphs of the efficiency change in a three-stage differential gear with the driving ring gear and the driven sun gear of the second stage, depending on the ratio and speed of the control link - the carrier

\section{4, DISCUSSION OF RESULTS}

The analytical expressions (15), (20), (27) and (34) have been obtained for determining the PE of the two- and three-stage gear differential transmissions of devices for controlling the change of speed through a carrier. With these expressions, it is possible to more accurately determine the PE of gear differentials with known angular velocity of the driving link, the angular velocity of the control link and the gear ratio. The obtained expressions for PE, with some minor transformations, can be applied in the case of any number of stages of the type of gear differentials under consideration. The calculation of PE for gear differentials with greater number of stages with the use of the developed effective method can be simplified by the use of computer technology. In this paper, graphic dependences for the PE of gear differentials, shown in fig. 4, 7, 9 and 11 , have been obtained by computer simulation. On the basis of these dependencies the possibility and expediency of application of such gear differentials in the machinery has been proved. Using this technique, you can determine the PE of gear transmissions with more than three stages and from the point of view of energy consumption and self-braking draw conclusions about their application in technology. It has been proved that the results of computer modeling are convenient to 
use, but for particular numerical parameters of multi-stage gear differentials should be known: angular velocity of a driving link, angular velocity of control link and gear ratios. Theoretical researches are the basis for further power calculations and experimental research of gear differential transmissions of speed change devices for the case when the driving link is the first-stage sun gear, and the driven link is the ring gear of the last stage or vice versa, while the control links are the carriers.

\section{CONCLUSIONS}

1. For the multistep differential gear of the speed change device with the driving sun gear and the driven ring gear, or vice versa, analytical dependencies are obtained to determine the efficiency. They are of practical importance for the development and design of such devices with an assessment of their energy effectiveness.

2. The resulting graphical dependences for the efficiency of two- and three-step differential gears allow us to follow the change in the efficiency value depending on the angular velocity of the control link - the carrier, the gear ratio and the number of stages. This allows us to assess the perfection of multi-stage differential gears in terms of energy costs and possible selfbraking.

3. With an increase in the number of steps of the differential gear, the efficiency decreases, which confirms the correctness of the obtained analytical regularities.

\section{REFERENCES}

1. Pawar PV, Kulkarni PR. Design of two stage planetary gear train for high reduction ratio. International Journal of Research in Engineering and Technology 2015; 6:150-157. https://doi.org/10.15623/ijret. 2015.0406025

2. Drewniak J, Garlicka P, Kolber A. Design for the biplanetary gear train. Scientific Journal of Silesian University of Technology. Series Transport 2016; 91: 5-17. https://doi.org/10.20858/sjsutst.2016.91.1

3. Li J, Hu Q, Zong Ch, Zhu T. Power analysis and efficiency calculation of multistage micro-planetary transmission. Energy Procedia 2017; 141: 654-659. https://doi.org/10.1016/j.egypro.2017.11.088

4. Wenjian Y, Huafeng D. Automatic detection of degenerate planetary gear trains with different degree of freedoms. Applied Mathematical Modelling. 2018; 64: 320-332.

https://doi.org/10.1016/j.apm.2018.07.038

5. Fuchun Y, Jianxiong F, Hongcai Z. Power flow and efficiency analysis of multi-flow planetary gear trains. Mechanism and Machine Theory 2015; 92: 86-99.

https://doi.org/10.1016/j.mechmachtheory.2015.05.003

6. Salgado DR, Castillo JM. Analysis of the transmission ratio and efficiency ranges of the four-, five-, and six-link planetary gear trains, Mechanism and
Machine Theory 2014; 73: 218-243.

https://doi.org/10.1016/j.mechmachtheory.2013.11.001

7. Peruń G. Verification of gear dynamic model in different operating conditions. Scientific Journal of Silesian University of Technology. Series Transport 2014; 84: 99-104.

8. Chao Ch, Jiabin Ch. Efficiency analysis of two degrees of freedom epicyclic gear transmission and experimental. Mechanism and Machine Theory 2015; 87: 115-130. https://doi.org/10.1016/j.mechmachtheory.2014.12.017

9. Tianli X, Jibin H, Zengxiong $\mathrm{P}$, Chunwang L. Synthesis of seven-speed planetary gear trains for heavy-duty commercial vehicle. Mechanism and Machine Theory 2015; 90: 230-239. https://doi.org/10.1016/j.mechmachtheory.2014.12.012.

10. Esmail EL, Pennestrì E, Hussein Juber A. Power losses in two-degrees-of-freedom planetary gear trains: A critical analysis of Radzimovsky's formulas. Mechanism and Machine Theory 2018; 128:191-204. https://doi.org/10.1016/j.mechmachtheory.2018.05.015

11. Dankov AM. Planetary continuously adjustable gear train with force closure of planet gear and central gear: from idea to design. Science \& Technique 2018;17(3): 228-237. (In Russian) https://doi.org/10.21122/2227-1031-2018-17-3-228-237

12. Dobariya M. Design of compound planetary gear train. International Journal for Research in Applied Science and Engineering Technology 2018; 6: 4: 3179-3184.

https://doi.org/10.22214/ijraset.2018.4527

13. Bonfiglio A, Lanzarotto D, Marchesoni M, Passalacqua M, Procopio R, Repetto M. Electricalloss analysis of power-split hybrid electric vehicles. Energies. 2017; 10(12):2142. https://doi.org/10.3390/en10122142.

14. Nutakor C, Kłodowski A, Sopanen J, Mikkola A, Pedrero JI. Planetary gear sets power loss modeling: Application to wind turbines. Tribology International 2017; 105: 42-54. https://doi.org/10.1016/j.triboint.2016.09.029.

15. Artobolevsky II. Theory of machines and mechanisms (in Russian). Mashynobuduvannya, Moskow $1988 ; 640$.

16. Kinytsky IT. Theory of mechanisms and machines (in Ukrainian). Naukova Dumka, Kyiv 2002; 660.

17. Augustyn S, Gębura A. Capabilities of the FAM-C method to diagnose the accessory gearboxes and transmission - train assemblies of the Mi-24 helicopters. Aviation Advances \& Maintenance

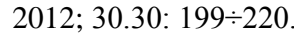

18. Malashenko V, Strilets O, Strilets V. Classification of methods and devices for the speed change control in technology (in Ukrainian). Pidyomno-transportna tekhnika, Odesa, 2015; 1: 70-78.

19. Strilets OR. Speed changes control by differential gear transmission through epicycle (in Ukrainian). Visnyk Ternopilskoho Natsionalnoho Tekhnichnoho Universytetu imeni Ivana Pulyuya, Ternopil, 2015; 4: 80: 129-135.

20. Malashenko V, Strilets O, Strilets V. Method and device for speed change by the epicyclical gear train with stepped-planet gear set. Research Works of AFIT 2016; 38: 13-19.

21. Malashchenko VO, Strilets OR, Strilets VM. Performance efficiency of the differential gear transmission in the device for speed changes control through the carrier (in Ukrainian). Visnyk NTU 
„KHPI”. Problemy mekhanichnoho pryvodu, Kharkiv, 2017; 25:1247: 97-102.

Received 2019-06-11

Accepted 2019-09-16

Available online 2019-09-18

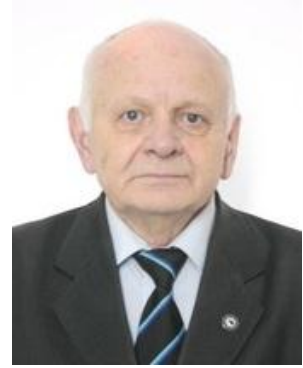

\section{Volodymyr \\ MALASHSCHENKO.}

Doctor of Technical sciences, is a professor and head of the Department of Technical Mechanics and Machines Parts at the Lviv Polytechnic National University. Specia-lizations: calculation of the dynamics of the lifting of high-rise structures; development of new drive clutches.

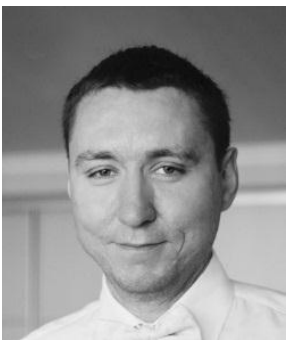

Oleh STRILETS. $\mathrm{PhD}$, is a associate professor on the Department of Analytical Mechanics, Engineering Graphics and Mechanical Engineering at the National University of Water and Environmental Engineering. Specializations: development of new constructions of elastic keyed joints. new devices for speed change;

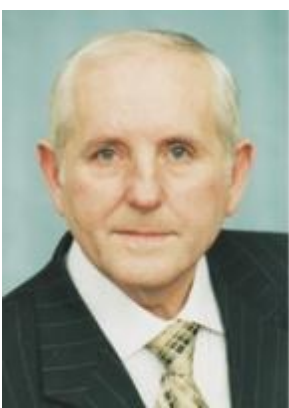

Volodymyr STRILETS.

$\mathrm{PhD}$, is a professor on the Department of Analytical Mechanics, Engineering Graphics and Mechanical Engineering at the National University of Water and Environmental Engineering. Specializations: development of new constructions of elastic, safe and inertial couplings; Improvement of shaft-hub type connections.

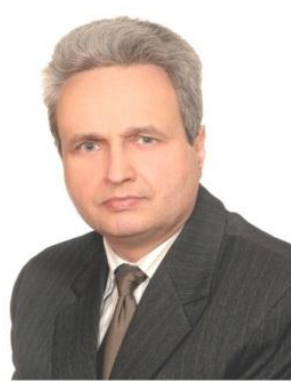

Sylwester KLYSZ.

Professor of Technical sciences, in Airworthiness Division on Air Force Institute of Technology in Warsaw and in Faculty of Technical Sciences on University of Warmia and Mazury in Olsztyn. Specializations: reliability and durability tests of aviation testing of aviation materials. components and structures, 